\title{
TRANSFORMASI HUNIAN DENGAN PERSPEKTIF SPASIAL DAN TATANAN BUDAYA: KOMPARASI PERMUKIMAN KUMUH BANG BUA, THAILAND DAN KAMPUNG NAGA, INDONESIA
}

\author{
M. Sesotyaningtyas ${ }^{\text {a }}$, W. D. Pratiwi ${ }^{\text {a }}$, J. S. Setyono ${ }^{\text {b }}$ \\ a Program Studi Arsitektur, SAPPK, Institut Teknologi Bandung, Indonesia \\ ${ }^{b}$ Kandidat Doktor, Fakultas Geografi, Universitas Gadjah Mada, Indonesia
}

\section{Article Info:}

Received: 9 September 2015

in revised form: 25 September 2015

Accepted: 5 October 2015

Available Online: 31 October 2015

\section{Keywords:}

Transformation, settlement, Culture,

Bang Bua, Kampung Naga

\section{Corresponding Author:}

Mega Sosetyaningtyas

Institut Teknologi Bandung,

Bandung, Indonesia

Email: megayulianto@gmail.com

Info Artikel:

Diterima: 9 September 2015

Hasil Revisi: 25 September 2015

Disetujui: 5 Oktober 2015

Publikasi On-Line: 31 Oktober 2015

Kata Kunci:

Transformasi, Hunian, Budaya, Bang Bua, Kampung Naga

Kontak Penulis:

Mega Sosetyaningtyas

Institut Teknologi Bandung,

Bandung, Indonesia

Email: megayulianto@gmail.com

Abstract: The change of cultural order within the community living in slum area of Bang Bua, Thailand and that of indigenous settlement of Kampung Naga, Indonesia has transformed the built environment. This research focused on the settlement transformation and was done in Bang Bua in 2010 and in Kampung Naga in 2014. The research applies qualitative methods combined with gathering spatial that are related to spatial composition of the settlement. The research adapts the concept of cultural order theory developed by Habraken (1998). It is found that the transformation of settlement can been viewed from cultural order perspective. It is indicated that the change in thinking framework, community behavior, and the consensuses among community member have contributed the transformation. They are also connected and embedded with the space where the people live.

\begin{abstract}
Abstrak: Perubahan tatanan budaya masyarakat pada kawasan permukiman kumuh Bang Bua, Thailand dan kawasan permukiman adat Kampung Naga, Indonesia, mampu mempengaruhi timbulnya transformasi hunian. Penelitian transformasi hunian ditinjau dari perubahan tatanan budaya, telah dilakukan di Bang Bua pada tahun 2010 dan Kampung Naga pada tahun 2014. Penelitian ini bersifat kualitatif dengan menggunakan metode pengumpulan data melalui observasi lapangan dan wawancara terhadap tokoh-tokoh masyarakat, para tetua, dan masyarakat Bang Bua serta Kampung Naga. Tahap analisis transformasi hunian mengacu pada konsep perubahan tatanan budaya (cultural order) yang telah dikemukan oleh Habraken (1998). Hasil penelitian menyatakan bahwa transformasi hunian dapat diamati melalui konsep perubahan tatanan budaya (cultural order). Terdapat indikasi bahwa fenomena transformasi hunian yang terjadi di Bang Bua dan Kampung Naga mempunyai persamaan dan perbedaan dalam beberapa hal, sebagai penyebabnya. Salah satu pemicu timbulnya fenomena transformasi hunian pada kedua kawasan tersebut adalah terdapatnya perubahan tatanan budaya pada masyarakat setempat, seperti perubahan pola pikir, cara pandang, perilaku masyarakat, hingga timbulnya kesepakatan-kesepakatan di antara masyarakat.
\end{abstract}

Copyright (C) 2015 GJGP-UNDIP This open access article is distributed under a Creative Commons Attribution (CC-BY-NC-SA) 4.0 International license.

How to cite (APA 6th Style):

Sesotyaningtyas, M., Pratiwi, W. D., \& Setyono, J. S. (2015). Transformasi hunian dengan perspektif spasial dan tatanan budaya: komparasi permukiman kumuh Bang Bua, Thailand dan Kampung Naga, Indonesia. Geoplanning: Journal of Geomatics and Planning, 2(2), 116-123. doi:10.14710/geoplanning.2.2.116-123

\section{PENDAHULUAN}

Setiap lingkungan memiliki hubungan yang secara keseluruhan tidak hanya disebabkan oleh struktur hierarki dari bentuk maupun tempat, tetapi dapat diamati melalui penggunaan struktur dan pola dari beberapa elemen yang khas. Lingkungan juga merupakan "artefak" yang di dalamnya terdapat hubungan antar lingkungan yang dapat mencerminkan suatu dimensi sosial. Hal ini mengindikasikan bahwa berbagai 
bentuk rumah akan selalu berkaitan dengan preferensi dan persepsi dari masing-masing penghuninya maupun budaya atau aturan tertentu yang berkembang di sekitarnya.

Di dalam lingkungan binaan terdapat berbagai hal tentang peraturan yang tidak terucap, seperti adat istiadat, kebiasaan, dan norma yang berlaku di dalamnya. Adanya perbedaan bentuk yang terjadi di dalam suatu lingkungan binaan dipengaruhi oleh berbagai aturan yang bersifat eksplisit dan implisit (adat dan kebiasaan). Untuk menyeimbangkan kedua hal tersebut, diperlukan adanya pembuatan aturan yang berkelanjutan, kesepakatan, dan konsensus/mufakat di antara para agen.

Penghuni atau masyarakat yang hidup dalam suatu lingkungan binaan memiliki peranan besar dalam mengendalikan berbagai perubahan yang terjadi pada hunian dan lingkungannya. Oleh sebab itu, perubahan-perubahan yang terjadi pada suatu lingkungan binaan selalu dipengaruhi oleh perubahanperubahan sosial budaya maupun pola aktivitas penghuni atau masyarakat yang mendiaminya secara langsung (Bukit et al., 2012). Berbagai perubahan yang terjadi terus menerus pada lingkungan binaan dapat memunculkan adanya fenomena transformasi.

Timbulnya fenomena transformasi hunian pada suatu kawasan permukiman diduga disebabkan oleh adanya pengaruh kuat dari perubahan-perubahan yang terjadi dalam tatanan budaya masyarakat. Adanya inkulturasi, akulturasi, proses dialog, hingga sintesis budaya yang muncul dalam kelompok masyarakat dapat menyebabkan pergeseran maupun perkembangan nilai-nilai suatu kebudayaan atau interaksi sosial dari masyarakat tertentu (Oetama, 1989; Sachari dan Sunarya, 2001). Perubahan-perubahan tatanan budaya dalam masyarakat memiliki intervensi untuk melakukan berbagai transformasi pada lingkungan di sekitarnya. Perubahan tatanan budaya masyarakat dapat diamati pada berbagai tempat, seperti perkampungan dengan adat istiadat yang cukup kuat hingga kawasan permukiman kumuh yang dapat tertata dengan baik. Berdasarkan buku "The Structure of the Ordinary" oleh N. J. Habraken (1998), transformasi tatanan budaya dapat diamati berdasarkan beyond control, the implicit, ways of sharing forms, words and forms, dan pattern.

Transformasi didefinisikan sebagai penambahan, pengurangan, dan perpindahan dari suatu elemen primer pada lingkungan binaan (Habraken, 1983). Transformasi dapat diamati melalui penafsiran sejarah (analisis diakronik) dan analisis jaringan / kondisi masa kini (analisis sinkronik) (Loeckx dan Vermeulen, 1986). Sedangkan, menurut Habraken (1983), transformasi dapat diamati berdasarkan tatanan bentuk, tatanan teritori, dan tatanan budaya. Transformasi yang diamati berdasarkan perubahan tatanan budaya, lebih memfokuskan pada hal-hal yang bersifat implisit. Hal-hal implisit tersebut seperti perubahan pola pikir, cara pandang, perubahan perilaku masyarakat, hingga timbulnya kesepakatan-kesepakatan di antara masyarakat.

Transformasi memiliki lima ciri tertentu, antara lain (1) transformasi terjadi secara perlahan-lahan; (2) awal dan akhir dari transformasi tidak dapat diduga karena tergantung dari latar belakang proses terjadinya; (3) transformasi bersifat komprehensif dan berkesinambungan; dan (4) transformasi selalu memiliki keterkaitan erat dengan system nilai yang ada di dalam masyarakat (Alexander, 1987 dalam Manik, 2007). Studi-studi terdahulu tentang fenomena transformasi hunian telah banyak membahas tentang transformasi hunian pada kawasan pecinan (Pakilaran, 2006; Tutuko, 2010); transformasi hunian akibat bencana alam (Weerasinghe dan Shigemura, 2008; Kobayashi et al., 2012); transformasi hunian vernakular (Chuapramet al.,2012); dan transformasi hunian tradisional (Ombeni dan Deguchi, 2009; Hanan, 2012; Sumanto dan Sarmini, 2013).

Transformasi hunian dalam suatu kawasan dapat terjadi secara bertahap seiring dengan perubahan yang terjadi pada lingkungan binaan dengan segala kekayaan dan kompleksitasnya, yang muncul secara informal dan terus bertahan selama berabad-abad. Lingkungan binaan berkembang dari struktur-struktur yang bersifat implisit berdasarkan pemahaman umum (Habraken, 1998). Selain itu, lingkungan binaan memiliki kehidupan mereka sendiri, dimana mereka dapat tumbuh, memperbaharui diri, dan mampu bertahan selama berabad-abad dan selalu mengikuti perkembangan zaman. Lingkungan binaan terdiri dari entitas fisik seperti bangunan, jalan atau infrastruktur, serta masyarakat yang tinggal di dalamnya. 


\section{DATA DAN METODE}

Penelitian untuk mengetahui komparasi transformasi permukiman kampung adat dan permukiman kumuh ini dilakukan melalui pengamatan perubahan tatanan budaya yang diduga sebagai faktor pemicu transformasi. Guna mengetahui hal tersebut, dilakukan kegiatan survei di kawasan permukiman kumuh Bang Bua (Thailand) pada tahun 2010 dan permukiman adat Kampung Naga (Bandung, Indonesia) pada tahun 2014 (Gambar 1).

Penelitian ini bersifat kualitatif yang dikombinasikan dengan pendekatan spasial dengan pengumpulan data melalui observasi lapangan dan wawancara terhadap tokoh-tokoh masyarakat, kepala dusun atau kampung, para tetua, dan masyarakat Bang Bua serta Kampung Naga. Transformasi permukiman pada masyarakat Bang Bua dan Kampung Naga dianalisis berdasarkan perubahan pada tatanan budaya masyarakatnya. Pengambilan sampel responden yang dilakukan selama survei diambil secara random pada setiap kawasan permukiman yang terdapat di lokasi penelitian.

\section{HASIL DAN PEMBAHASAN}

\subsection{Kawasan Permukiman Kumuh Bang Bua (Thailand)}

Bang Bua merupakan salah satu kawasan permukiman kumuh di sekitar kanal Bang Bua yang telah berhasil ditata oleh Community Organizations Development Institute (CODI) melalui Program Baan Mankong pada tahun 2004. Pada mulanya, lahan di sekitar kanal Bang Bua berupa lahan kosong milik pemerintah yang dimanfaatkan sebagai lahan pertanian, sedangkan kanal Bang Bua dimanfaatkan sebagai titik utama kegiatan perdagangan di Bangkok. Mayoritas penduduk di sekitar kanal Bang Bua merupakan masyarakat berpenghasilan rendah yang berasal dari Timur Laut Thailand untuk mencari pekerjaan di Bangkok. Lokasi kanal Bang Bua ini sekitar $10 \mathrm{Km}$ di sebelah Utara Bangkok dan termasuk dalam Kecamatan Bang Khen. Faktor-faktor yang memicu timbulnya permukiman kumuh di Thailand antara lain tingkat urbaniasasi yang tinggi serta ketidakmampuan pemerintah dalam menyediakan rumah dan infrastruktur yang terjangkau bagi masyarakat berpenghasilan rendah. Untuk mengatasi masalah tersebut, pemerintah Thailand mengupayakan suatu penataan permukiman kumuh melalui Program Baan Mankong.

Baan Mankong merupakan suatu program perumahan baru yang mendudukan komunitas miskin sebagai pengendali program nasional dalam mencari solusi kemprehensif atas masalah perumahan, penetapan lahan, dan pelayanan dasar di kota-kota Thailand (UN-Habitat, 2008). Baan Mankong menyalurkan dana pemerintah dalam bentuk subsidi infrastruktur dan pinjaman lunak perumahan secara langsung kepada masyarakat miskin agar masyarakat dapat merencanakan dan melaksanakan berbagai upaya perbaikan lingkungan perumahan secara mandiri (Boonyabancha, 2005). Melalui bantuan perbaikan permukiman kumuh ini, Bang Bua menjadi kawasan permukiman yang lebih tertata dan bersih, kepemilikan lahan lebih jelas dan legal, serta tersedia infrastruktur dasar dan fasilitas publik yang memadai.

Gambar 1. Kawasan Permukiman Bang Bua, Thailand (Skala 1: 100 m) (Citra satelit, 2010)

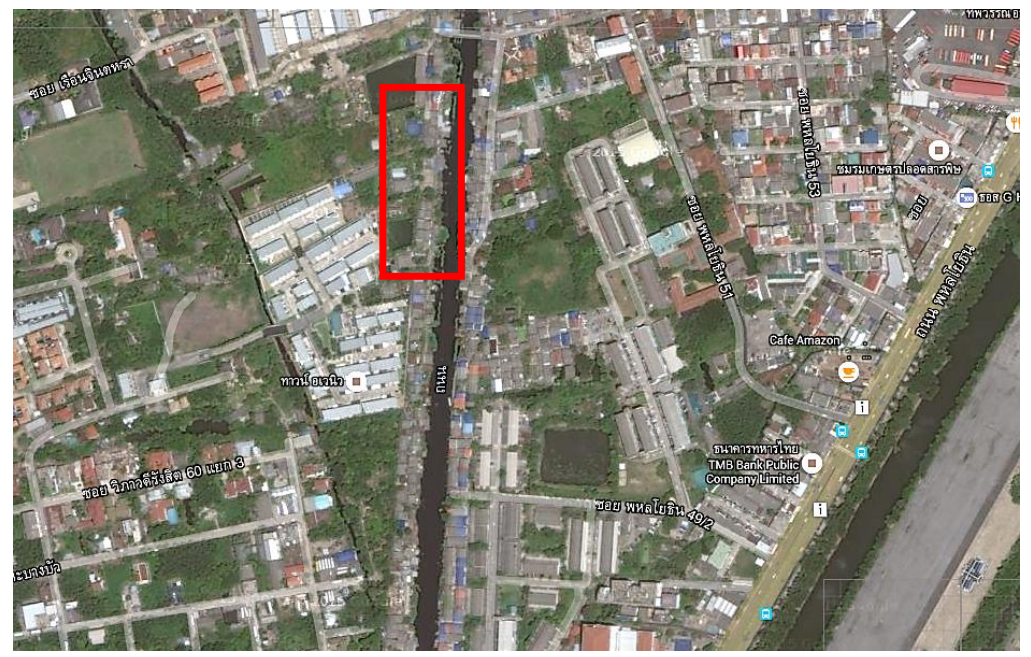




\subsection{Transformasi Kondisi Fisik Hunian di Bang Bua}

Perbaikan hunian dan lingkungan di Bang Bua dilakukan dengan melibatkan masyarakat secara langsung dalam setiap tahapan pembangunan, seperti perencanaan, pembuatan siteplan, penataan rumah, hingga dalam proses membangun rumah. Perawatan kondisi lingkungan tempat tinggal di sekitar kanal Bang Bua diwajibkan dikelola oleh masyarakat secara mandiri. Perbandingan kondisi fisik hunian pada komunitas Bang Bua saat sebelum dan setelah perbaikan permukiman dapat dilihat pada Tabel 1, Gambar 2 dan 3.

Tabel 1. Perbandingan Kondisi Fisik Hunian di Bang Bua (Analisis, 2010)

\begin{tabular}{|c|c|c|}
\hline Perbandingan & Sebelum & Setelah \\
\hline Bahan bangunan & Kayu & $\begin{array}{l}\text { Lantai dari keramik, atap dari kayu atau asbes, serta dinding dari batu } \\
\text { bata dan semen }\end{array}$ \\
\hline Model Rumah & Rumah panggung dari kayu & $\begin{array}{l}\text { - Detached house (satu rumah, satu atap) } \\
\text { - Double "twin" house (dua rumah dengan satu atap) } \\
\text { - Row house yang dapat dihuni oleh } 2 \text { KK dengan negosiasi di antara } \\
\text { dua KK tersebut }\end{array}$ \\
\hline Ukuran rumah & Tidak jelas & Sekitar $25 \mathrm{~m}^{2}-50 \mathrm{~m}^{2}$ dan beberapa rumah terdiri dari 2 lantai. \\
\hline Ruang terbuka & Tidak ada & $\begin{array}{l}\text { Setiap rumah terdapat taman kecil seluas } \pm 2 \mathrm{~m}^{2} \text { pada halaman depan } \\
\text { rumah }\end{array}$ \\
\hline $\begin{array}{l}\text { Pembagian dan } \\
\text { penggunaan ruang }\end{array}$ & Ruang multi-fungsi & $\begin{array}{l}\text { Pembagian ruang lebih jelas seperti tempat tidur, ruang keluarga, } \\
\text { kamar mandi, dapur, dan sebagainya. }\end{array}$ \\
\hline Sanitasi & Toilet komunal di kanal & Setiap rumah memiliki kamar mandi di rumah \\
\hline Lokasi permukiman & $\begin{array}{l}\text { Di sepanjang kanal hingga ke } \\
\text { badan air }\end{array}$ & $\begin{array}{l}\text { Menjauhi kanal sekitar 3-5 meter dan di batasi oleh jalan lingkungan } \\
\text { selebar 2-3 meter }\end{array}$ \\
\hline $\begin{array}{l}\text { Kondisi lingkungan } \\
\text { hunian }\end{array}$ & $\begin{array}{l}\text { Lingkungan sangat buruk, kotor, } \\
\text { dan tidak terawat }\end{array}$ & $\begin{array}{l}\text { Kondisi lingkungan lebih bersih dan tertata, memiliki taman di halaman } \\
\text { rumah, memiliki ruang terbuka publik, serta rumah yang dicat }\end{array}$ \\
\hline $\begin{array}{l}\text { Ketersediaan } \\
\text { Infrastruktur }\end{array}$ & Tidak tersedia & $\begin{array}{l}\text { Infrastruktur disediakan oleh pemerintah, terdapat pengelolaan } \\
\text { limbah yang dibuat secara swadaya oleh komunitas, penyediaan } \\
\text { tempat sampah yang dipisahkan menurut jenisnya (organik dan } \\
\text { anorganik), fasilitas kesehatan (puskesmas), fasilitas kesehatan, } \\
\text { playground, dan daycare. }\end{array}$ \\
\hline $\begin{array}{l}\text { Pencahayaan dan } \\
\text { Sirkulasi udara }\end{array}$ & Sangat buruk & Sudah cukup baik \\
\hline
\end{tabular}

Gambar 2. Kondisi Hunian di Sekitar Kanal Bang Bua Sebelum Perbaikan (Penulis, 2010)

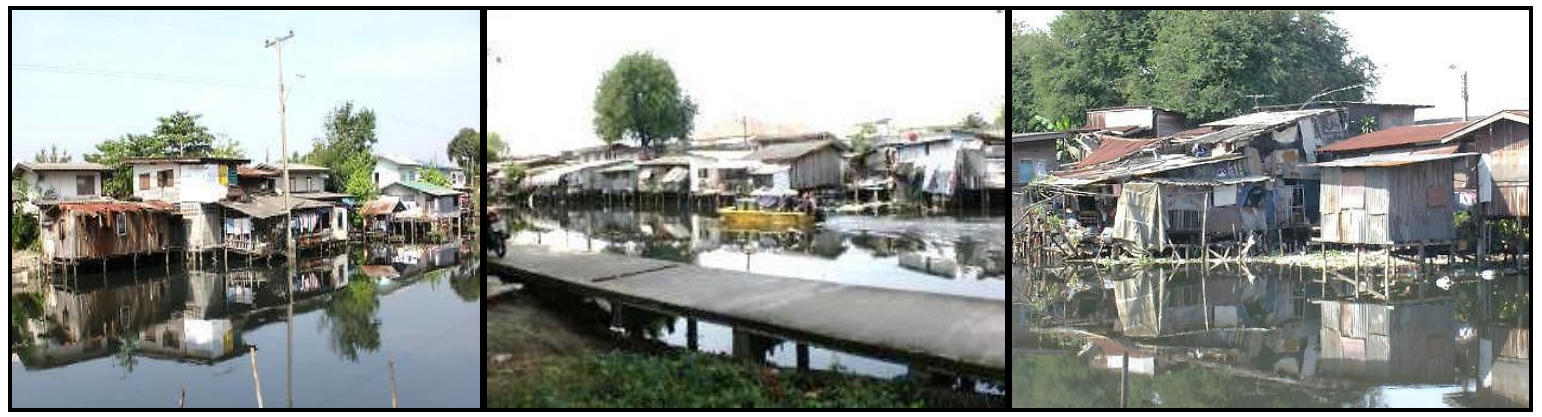

Gambar 3: Kondisi Hunian di Sekitar Kanal Bang Bua Setelah Perbaikan (Penulis, 2010)

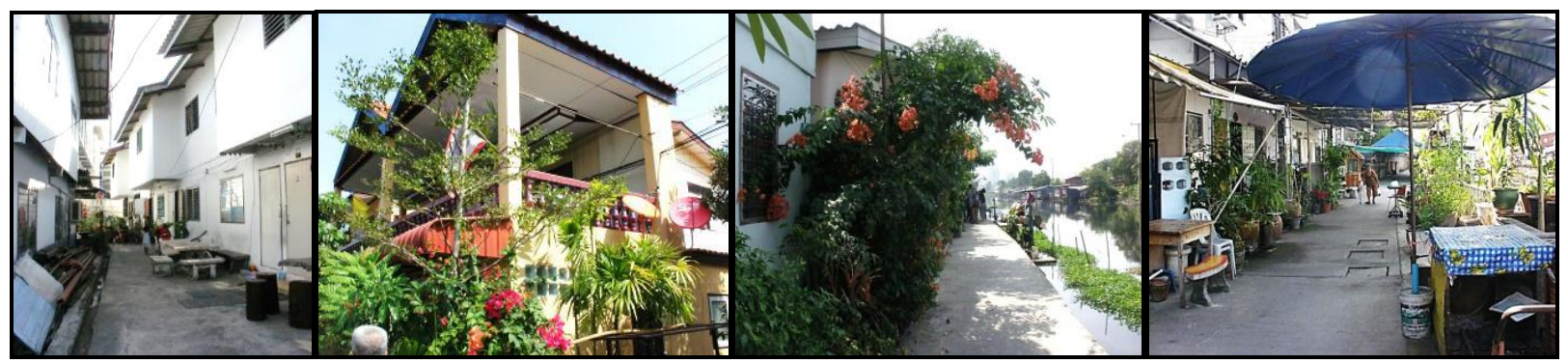




\subsection{Kawasan Permukiman Adat Kampung Naga (Indonesia)}

Kampung Naga merupakan sebuah perkampungan yang dihuni oleh sekelompok masyarakat yang sangat kuat dalam memegang adat istiadat peninggalan leluhurnya, dalam hal ini adat Sunda dan masih lestari hingga saat ini. Kawasan permukiman Kampung Naga terletak di lembah yang subur, di Desa Negalsari, Kecamatan Salawu, Kabupaten Tasikmalaya. Luas area Kampung Naga adalah sekitar 1,5 ha. Kondisi lingkungan Kampung Naga sangat hijau, sejuk, dan asri. Secara umum, masyarakat Kampung Naga dibagi menjadi dua kelompok, yaitu kelompok masyarakat Kampung Naga (di dalam kawasan Kampung Naga) dan kelompok masyarakat Kampung Sanaga (di luar kawasan Kampung Naga) (Gambar 4). Sistem pemerintahan Kampung Naga terbagi menjadi dua, yaitu 1) sistem pemerintahan non formal (tradisional), terdiri dari kuncen, punduh, dan lebe. 2) sistem pemerintahan formal, seperti kepala kampung, RT, dan RW.

Jumlah bangunan di Kampung Naga seluruhnya berjumlah 111, terdiri dari 108 rumah, 1 balai patemon, 1 masjid, dan 1 Bumi Ageung yang digunakan untuk ritual adat. Bentuk rumah masyarakat Kampung Naga berbentuk rumah panggung dengan material bangunan dari bambu dan kayu alba, serta di cat dengan kapur. Atap rumah harus terbuat dari nipah, ijuk, atau alang-alang. Rumah menghadap ke arah utara atau selatan dengan memanjang ke arah barat dan timur guna mendapatkan pencahayaan dan sirkulasi udara yang baik (Wibowo, 2012; Kusuma, 2013) (Gambar 5).

Gambar 4. Kawasan Permukiman Kampung Naga, Indonesia (Skala 1: 50 m) (Citra Satelit, 2014)

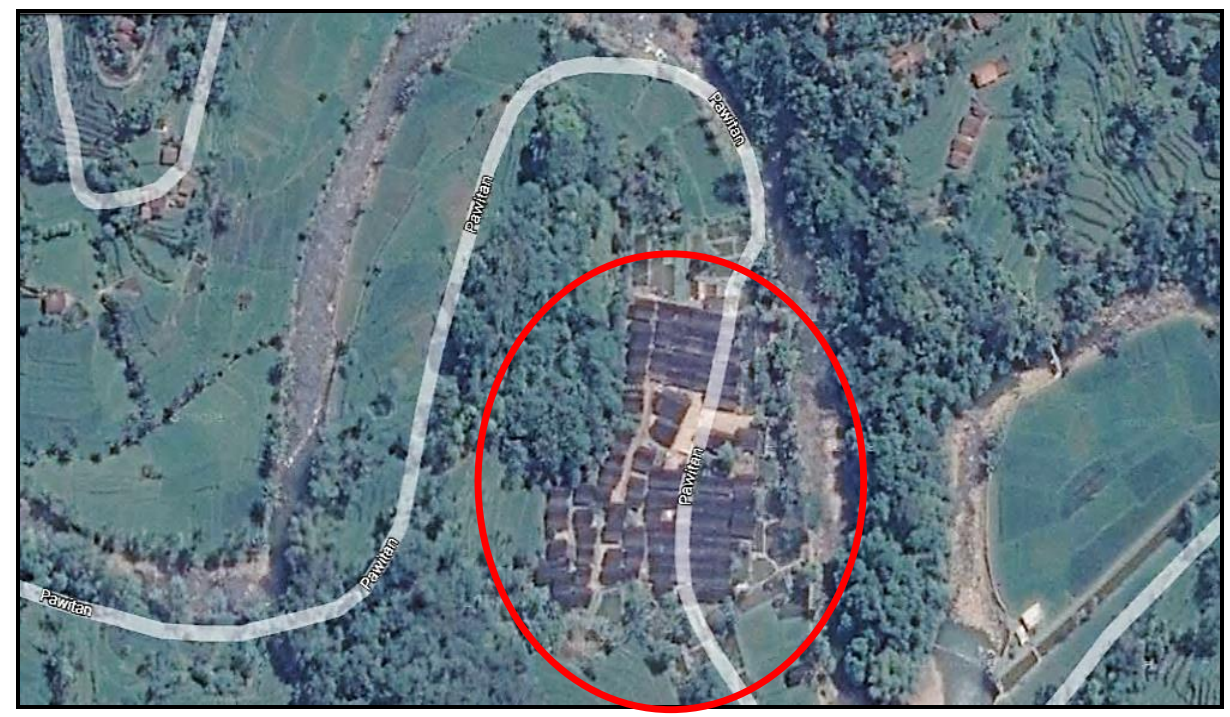

Gambar 5. a. Permukiman Kampung Naga; b dan c. Rumah penduduk yang telah mengalami penambahan ruang (Analisis, 2014)

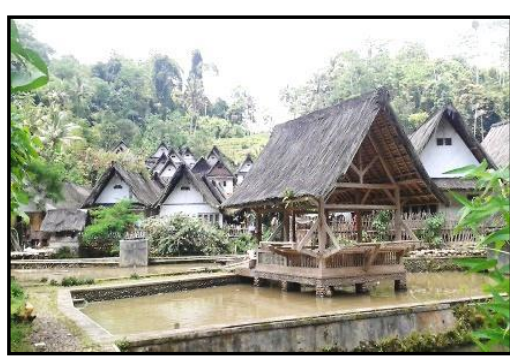

a.

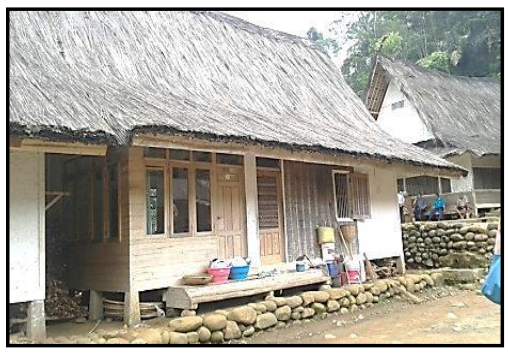

b.

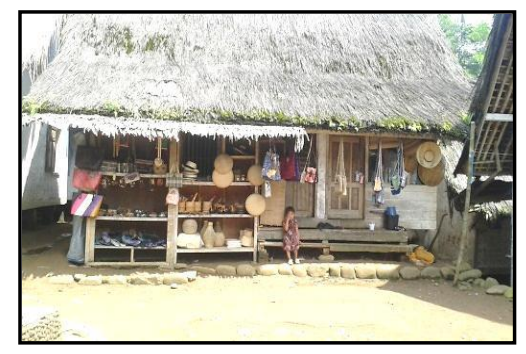

C.

\subsection{Perubahan Tatanan Budaya Masyarakat Bang Bua}

Program penataan permukiman kumuh di Bang Bua berdampak pada perubahan kondisi sosial dan budaya masyarakat Bang Bua. Sebelum adanya perbaikan permukiman, kondisi masyarakat Bang Bua sangat tidak terorganisir dan beberapa penduduk bekerja sebagai penjual obat-obatan terlarang. Setelah 
kondisi hunian telah tertata dengan baik, sebagian dari penjual obat-obatan terlarang ini mulai sadar dan beralih profesi menjadi buruh bangunan, pedagang kaki lima, pedagang pasar, satpam, dan sebagainya, sedangkan sebagian lainnya di penjara.

Untuk tetap mempertahankan kerukunan dan mencegah timbulnya kesenjangan sosial diantara masyarakat, mereka membuat suatu kebijakan-kebijakan khusus, antara lain:

a) Pembuatan jalan lingkungan hanya selebar 2-3 meter. Jalan lingkungan ini hanya dapat dilalui oleh kendaraan beroda dua, sedangkan kendaraan roda empat hanya diperbolehkan masuk bila dalam keadaan darurat. Hal ini dimaksudkan agar tidak timbul kesenjaangan sosial di antara penduduk.

b) Bagi penduduk yang ingin merenovasi rumah, harus terlebih dahulu melaporkannya pada ketua komunitas dan membuat kesepakatan dengan penduduk di sekitarnya.

c) Terdapat tata cara membayar sumbangan bulanan untuk perawatan lingkungan permukiman, peraturan pembagian lahan, penataan taman kecil pada halaman rumah, hingga peraturan khusus yang menyatakan bahwa kawasan permukiman Bang Bua tidak diperuntukan bagi penduduk golongan ekonomi menengah ke atas.

Perubahan perilaku dan kepatuhan masyarakat Bang Bua terhadap berbagai peraturan yang berlaku tersebut menggambarkan bahwa terdapat adanya perubahan tatanan budaya dalam pola hidup masyarakat Bang Bua. Terjadinya perubahan tatanan budaya ini diduga disebabkan oleh keikutsertaan seluruh anggota masyarakat dalam setiap tahap pembangunan, seperti tahap pembuatan siteplan, pentaan rumah, penataan lanskap lingkungan, hingga tahap membangun rumah. Keikutsertaan seluruh masyarakat dalam setiap tahap pembangunan tersebut menimbulkan "sense of belonging" terhadap rumah dan lingkungan tempat tinggal mereka. Sense of belonging secara perlahan mampu merubah cara pandang, perilaku, dan pola pikir masyarakat setempat. Oleh sebab itu, sejak tahun 2004 hingga tahun 2010, seluruh masyarakat Bang Bua mampu menjaga kondisi lingkungan permukimannya agar tetap rapi, asri, dan bersih meskipun perawatan dan operasionalnya telah diserahkan sepenuhnya kepada masyarakat setempat.

\subsection{Perubahan Tatanan Budaya Masyarakat Kampung Naga}

Pada mulanya, Kampung Naga merupakan kawasan perkampungan yang masih kuat adat istiadatnya dan sangat terisolasi dari dunia luar. Dalam menganut kepercayaan, masyarakat Kampung Naga sangat berpedoman pada warisan adat istiadat yang diberikan oleh para leluhur atau karuhun (http://id.wikipedia.org/wiki/Kampung_Naga). Masyarakat Kampung Naga memiliki pola hidup bertetangga yang selalu bergotong royong sejak dulu kala. Pantangan atau pamali bagi masyarakat Kampung Naga masih dilaksanakan dengan patuh dalam kehidupan sehari-hari, seperti tata cara membangun rumah, bentuk rumah, letak, arah rumah, material bangunan, pakaian upacara, dan sebagainya

Saat ini, hal-hal yang bersifat implisit seperti pantangan mulai dipertimbangkan eksistensinya. Hal tersebut terlihat pada beberapa rumah penduduk yang mulai merubah bentuk dan pembagian ruangnya. Perubahan hunian penduduk ini tidak terjadi begitu saja. Berdasarkan wawancara dengan Punduh (kepala kampung), dikatakan bahwa saat wisata akan masuk ke dalam Kampung Naga dan timbulnya keinginan penduduk untuk merubah huniannya, memunculkan berbagai perdebatan panjang antara kepala adat dan seluruh anggota masyarakat. Perdebatan tersebut berakhir dengan menghasilkan sebuah kesepakatan di antara kepala adat dan seluruh anggota masyarakat. Kesepakatan tersebut antara lain (1) penggunaan material rumah yang tetap sama; (2) bentuk rumah asli tidak diperbolehkan berubah; (3) perubahan rumah hanya diperbolehkan berupa penambahan ruang di sisi rumah asli; serta (4) masyarakat tetap harus mempertahankan adat istiadat kampung.

Pada dasarnya, keinginan penduduk merubah huniannya ini dimaksudkan untuk menyediakan berbagai kebutuhan bagi para wisatawan seperti tempat menginap maupun cinderamata. Transformasi hunian penduduk yang terjadi di Kampung Naga turut serta diiringi dengan timbulnya perubahan tatanan budaya di sekitarnya. Bentuk perubahan tatanan budaya pada penduduk tidak hanya perubahan pola pikir dan cara pandang dengan merubah huniannya guna memfasilitasi para wisatawan, tetapi juga perilaku masyarakat Kampung Naga yang mulai terbuka dengan kedatangan masyarakat umum. 


\section{KESIMPULAN}

Berdasarkan konsep perubahan tatanan budaya, ditemukan bahwa perubahan tatanan budaya dalam masyarakat yang mendiami suatu kawasan permukiman memiliki pengaruh yang besar bagi keberlanjutan permukiman tersebut. Adanya berbagai perubahan pada pola pikir, cara pandang, perubahan perilaku masyarakat, hingga timbulnya kesepakatan-kesepakatan di antara masyarakat menjadi kunci penting dalam mengatur keseimbangan yang bersifat implisit dan eksplisit di dalam suatu kawasan permukiman. Perubahan tatanan budaya dalam masyarakat tersebut nampak pada timbulnya fenomena transformasi hunian di permukiman kumuh Bang Bua serta Kampung Naga. Fenomena transformasi hunian pada keduanya memunculkan persamaan dan perbedaan.

Persamaan diantara kedua lokasi ini adalah adanya penambahan ruang pada hunian penduduk. Sedangkan perbedaannya adalah pada permukiman Kampung Naga tidak terdapat fenomena transformasi permukiman, baik pola permukimannya maupun material hunian yang digunakan. Kondisi tersebut disebabkan oleh adanya tradisi dan kepercayaan yang cukup kuat di dalam masyarakat Kampung Naga untuk tidak merubah material hunian maupun pola permukimannya. Pada kawasan permukiman kumuh Bang Bua, terdapat fenomena transformasi pola permukiman maupun kondisi hunian yang cukup signifikan dari kondisi kumuh menjadi layak huni dan sehat.

\section{DAFTAR PUSTAKA}

Boonyabancha, S. (2005). Baan Mankong: going to scale with "slum" and squatter upgrading in Thailand. Environment and Urbanisation, 17, pp. 21-46.

Bukit, E.S., Himasari H., \& Arif S. W. (2012). Aplikasi Metode N. J. Habraken pada Studi Transformasi Permukiman Tradisional. Jurnal Lingkungan Binaan Indonesia, 1, 51-62.

Chuapram, S., King, R., \& Panin, O. (2012). Transformation of Local Living: Buddhist Thai Communities and Vernacular Houses around Songkhla Lake Basin. Procedia Social and Behavioral Sciences, 50, 42 54.

Habraken, N. J. (1983). Transformations of The Site. Cambridge: A Water Press

Habraken, N. J. (1998). The Structure of the Ordinary: Form and Control in the Built Environment. Cambridge: The MIT Press

Hanan, H. (2012). Modernization and Cultural Transformation: The Expansion of Tradisional Batak Toba House in Huta Siallagan. Procedia Social and Behavioral Sciences, 50, $800-811$.

Http://id.wikipedia.org/wiki/Kampung_Naga

Kobayashi, H., Thanh, D. T., \& Tanaka, U. (2012). Housing Conditions of a Lagoon Village in a Flood-prone Area of Central Vietnam. Journal of Asian Architecture and Building Engineering, 11, $79-85$.

Kusuma, Barry. (2013). Mengunjungi dan Mempelajari Budaya Kampung Naga.[Online].Tersedia di: http://travel.kompas.com/read/2013/09/18/0812396/Mengunjungi.dan.Mempelajari.Budaya.Kam pungNaga. [Diakses 15 Desember 2014]

Loeckx, A., \& Vermeulen, P. (1986). Note on the Methodology of Urban Analysis. Leuven: Katholieke Universiteit Leuven

Manik, I. W. Y. (2007). Pengaruh Demografi, Gaya Hidup, dan Aktifitas Terhadap Transformasi TipoMorfologi Hunian Tradisional di Desa Bayung Gede, Bali, Tesis Program Magister. Tidak Dipublikasikan. Bandung: Institut Teknologi Bandung.

Oetama, J. (1989). Transformasi Kebudayaan: Dalam Menerawang Masa Depan Ilmu Pengetahuan, Teknologi, dan Seni. Bandung: Institut Teknologi Bandung

Ombeni, S. \& Deguchi, A. (2009). Transformation of Residential Units into Commercial Spaces in the Central Business District of Dar es Salaam, Tanzania. Journal of Asian Architecture and Building Engineering, 8, $159-166$.

Pakilaran, A. U. (2006). Transformasi Bentuk dan Ruang pada Rumah Toko di Kawasan Pecinan, Makassar (1970 - 2005), Tesis Program Magister. Tidak Dipublikasikan. Bandung: Institut Teknologi Bandung.

Sachari, A. \& Yan, S. (2001). Wacana Transformasi Budaya. Bandung: ITB

Sumanto \& Sarmini. (2013). Transformasi Pemukiman Komunitas Madura (Studi Kasus di Desa Lembung Peseser Kecamatan Sepulu Kabupaten Bangkalan. Kajian Moral dan Kewarganegaraan, 1, 212 231. 
Tutuko, P. (2010). Community Attachment pada Transformasi Desain Bangunan Permukiman di Sekitar Kawasan Pecinan. Local Wisdom, 2, $10-19$.

UNESCAP \& UN-HABITAT. (2008). Panduan Ringkas Untuk Pembuatan Kebijakan: Perumahan Bagi Kaum Miskin Di Kota-kota Asia. (Terj.) Wicaksono Sarosa, dkk. 2009. Penanganan Lingkungan Perumahan dan Permukiman Kumuh (PLP2K-BK) Tahun Anggaran 2010. Jakarta: UN-ESCAP and UN-HABITAT

Weerasinghe, W. K. \& Shigemura, T. (2008). A Study on Transformation of Living Environment and Domestic Spatial Arrangements: Focused on a Western Coastal Housing Settlement of Sri Lanka after Sumatra Earthquake and Tsunami 2004. Journal of Asian Architecture and Building Engineering, 7, 285 - 292.

Wibowo, A. S. (2012). Arsitektur Vernakular Dalam Perubahan: Kajian Terhadap Arsitektur Kampung Naga, Jawa Barat. Prosiding Temu IImiah IPLBI, 53-56. 